\title{
Learning the Anatomy of a Community: An Interprofessional Initiative
}

\author{
Julie E. Miller-Cribbs \& Sheila M. Crow \\ University of Oklahoma School of Community Medicine, Tulsa, OK USA
}

\begin{abstract}
Much like healthcare learners need to know human anatomy, they similarly need to know the community in which they live and the patients they will serve. In 2008, the University of Oklahoma College of Medicine established the School of Community Medicine (SCM) track to equip future healthcare professionals with skills to address health disparities and improve the health of the community. The Summer Institute (SI), now in its sixth year, is a hallmark of the SCM track, exposing students to principles and practices of community medicine through an innovative interprofessional education (IPE) initiative.
\end{abstract}

The SI is six consecutive days and requires more than 40 clock hours of participation. Approximately 130 faculty and students from allied health, medicine, nursing, pharmacy, social work, and education are divided into interprofessional teams of four students and two faculty members. Across the week they participate in experiential activities that encourage problem solving, critical thinking, and team work. There is a daily anchoring lecture delivered by interdisciplinary faculty teams, a lunchtime World Café conversation for learners across teams to discuss their experiences, and a "professional meaning" conversation within teams to explore the professional values taking shape. Learners also travel in car groups to interview patients in their homes, directors of community service agencies, and healthcare providers. They work as interprofessional teams to shadow patients in the community health clinic system and spend one afternoon immersed in a poverty simulation, attempting to keep their simulated family afloat, while navigating social service systems and confronting the pressures of life at the poverty line. Finally, students and faculty form new

Corresponding author: Sheila M. Crow, PhD, University of Oklahoma School of Community Medicine, Tulsa, OK, USA;

Tel: +1-918-66o-3814; Fax: +1-918-660-3090;

Email: $\underline{\text { Sheila-crow@ouhsc.edu }}$ interprofessional teams to address problems of common interest and prototype solutions, which are evaluated by the entire group of participants on the last day of the SI.

We have extensive quantitative and qualitative data and are examining the longitudinal impact of the SI on students as they progress through their professional careers. Medical and Physician Assistant students, for example, are being tracked to determine if their IPE attitudes change over time and if they are different than non-SI participants. While initial findings are promising, the long-term impact of the SI is unknown.

\section{Acknowledgements}

The authors would like to thank Kent Teague, Ph.D., Justin Van De Wiele, Ph.D., and Meredith Davison, Ph.D. for providing input in the manuscript and their commitment to the Summer Institute.

\section{Keywords}

Community

\section{Notes on Contributors}

JULIE E. MILLER-CRIBBS, is Professor, University of Oklahoma School of Community Medicine, Tulsa, OK, USA.

SHEILA M. CROW, is Associate Professor, University of Oklahoma School of Community Medicine, Tulsa, OK, USA. 